\title{
Multi-objective modeling, uncertainty analysis, and optimization of reversible solid oxide cells
}

\author{
Zahra Salehi ${ }^{1} \cdot$ Iman Gholaminezhad ${ }^{2}$
}

Received: 31 October 2017 / Accepted: 7 March 2018 / Published online: 19 March 2018

(c) The Author(s) 2018

\begin{abstract}
Reversible solid oxide cells can provide efficient and cost-effective scheme for electrical-energy storage applications. However, this technology faces many challenges from material development to system-level operational parameters, which should be tackle for practical purposes. Accordingly, this study focuses on developing novel robust artificial intelligence-based blackbox models to optimize operational variables of the system. A genetic-programming algorithm is used for Pareto modeling of reversible solid oxide cells in a multi-objective fashion based on experimental input-output data. The robustness of the obtained optimal model evaluated using Monte Carlo simulations technique. An optimization study adopted to optimize the operating parameters, such as temperature and fuel composition using a differential evolution algorithm. The objective functions that have been considered for Pareto multi-objective modeling process are training error and model complexity. In addition, the discrepancy between maximum and minimum output voltage in the whole operation of the system is chosen as the optimization process objective function. The robustness of the optimal trade-off model is shown in terms of statistical indices for varied uncertainty levels from 1 to $10 \%$. The optimized operational condition based on the suggested model reveals optimal intermediate temperature of $762{ }^{\circ} \mathrm{C}$ and fuel mixture of about $29 \% \mathrm{H}_{2}, 25 \% \mathrm{H}_{2} \mathrm{O}$, and $14 \% \mathrm{CO}$.
\end{abstract}

Keywords Reversible solid oxide cell $\cdot$ Multi-objective $\cdot$ Genetic programming $\cdot$ Pareto $\cdot$ Monte Carlo simulations

\begin{tabular}{ll}
\multicolumn{2}{l}{ Abbreviations } \\
$X$ & Random variable \\
$f_{X}(x)$ & Probability density function \\
$F_{X}(x)$ & Cumulative distribution function \\
$\mu(X)$ & Mean \\
$\sigma^{2}(X)$ & Variance \\
$N$ & Number of samples \\
$f(x)$ & Probability distribution \\
$X_{\mathrm{i}}$ & ith design variable \\
$x_{\mathrm{i}}$ & Mole fraction of species \\
$I$ & Current density $\left(\mathrm{A} \mathrm{cm} \mathrm{cm}^{-2}\right)$ \\
$T$ & Temperature $\left({ }^{\circ} \mathrm{C}\right)$ \\
$V_{\text {out }}$ & Output voltage $(\mathrm{V})$ \\
$\mathrm{R} 2$ & Correlation coefficient \\
$\mathrm{OCV}$ & Open circuit voltage $(\mathrm{V})$
\end{tabular}

Iman Gholaminezhad g201790037sg@jindai.jp

1 Department of Materials Science and Engineering, School of Engineering, Shiraz University, Shiraz, Iran

2 Department of Materials and Life Chemistry, Kanagawa University, 3-27-1, Rokkakubashi, Kanagawa-ku, Yokohama, Kanagawa 221-8686, Japan

$$
\begin{array}{ll}
P & \text { Power density }\left(\mathrm{W} \mathrm{cm}^{-2}\right) \\
\eta_{\mathrm{tot}, i} & \text { Total overpotential in } i \text { mode of operation } \\
\mathrm{Obj}_{\text {fun }} & \text { Objective function }
\end{array}
$$

\section{Introduction}

As part of the efforts to develop new energy conversion systems, there is great interest of using standalone or hybrid renewable energy systems that can help meeting the future demand [1]. In this regard, reversible solid oxide cells receiving increasing scientific and industrial interest. Reversible solid oxide cells (RSOCs) are single-unit, all solid-state, electrochemical devices that can operate in both the fuel cell (SOFC) and electrolysis (SOEC) mode, thus acting as flexible energy conversion and storage systems, particularly to store intermittent renewable energy, such as wind or solar [2-4]. A reversible fuel cell can take advantage of excess electrical grid capacity during off-peak hours to produce hydrogen fuel, to be utilized later during periods of high electrical demand $[5,6]$.

Artificial intelligence (AI) techniques, such as artificial neural networks (ANNs), support vector machines (SVM), 
and genetic programming (GP), are useful methods for black-box modeling of electrochemical systems [7-11]. GP uses the concept of evolutionary computing based on Darwinian theory and natural selection to search over complex space of models to find the global optimum one [12]. There are just few studies on fuel cell system modeling using GP, while there is not any paper on RSOCs using AI techniques.

Chakraborty [13] used GP for static and dynamic modeling of solid oxide fuel cells. He well showed the superiority of GP compared to radial basis function neural networks in various modeling approaches. Chakraborty [14] also applied GP for modeling and simulation of SOFC output voltage versus fuel utilization behavior. Nazari [15] utilized GP for output voltage prediction of PEM fuel cells. In his study, variety of input parameters, such as current density, fuel cell temperature, anode and cathode humidification temperature, operating pressure, fuel cell type, and oxidant flow rate, are considered.

There are also various optimization studies on SOFCs from various operational and microstructural aspects based on mathematical and artificial intelligence models. Bozorgmehri and Hamedi [16] proposed a neural network model of anode-supported SOFC. They used a genetic algorithm to optimize the neural network model to improve the performance of SOFC. Behzadi and Roshandel [17] implemented multi-objective optimization of SOFC stack by considering the effects of fuel utilization and hydrogen cost. Quddus et al. [18] implemented multi-objective optimization for oxidative coupling of methane using genetic algorithms by considering maximization of power and $\mathrm{C}_{2}$ selectivity and also minimization of the production of undesired side products $\left(\mathrm{CO}_{\mathrm{x}}\right)$. Borji et al. [19] optimized the performance of an anode-supported methane fed SOFC by obtaining a tradeoff between system efficiency and output power considering pre-reforming rate, fuel utilization, air ratio, average current density, and steam-to-carbon ratio as design variables. More recently, Gholaminezhad et al. [20] applied a multi-objective optimization and uncertainty analysis of methane fed SOFCs for maximum power density and efficiency performance achievement.

This is while, there is not any work regarding optimization of reversible solid oxide cells in the literature. In this work, a differential evolution algorithm is used to optimize a developed genetic-programming-based RSOC model for maximum performance.

Uncertainty analysis of the obtained optimum design also is important for practical purposes due to various sources of uncertainties in real operation of the system. Such uncertainty analysis can be accomplished by sensitivity analysis tools and sampling methods such as Monte Carlo simulations (MCSs) [21, 22] and Latin hypercube sampling (LHS) [23]. MCS is a direct and simple numerical method for uncertainty quantification and is used in this research for stochastic analysis of obtained optimum design solutions [21]. It generates random samples considering pre-defined probabilistic distributions for uncertain parameters.

In this study, a multi-objective genetic-programming algorithm is deployed for modeling reversible solid oxide cells considering various operational parameters. The objective functions that have been considered for multi-objective modeling process are training error and model complexity. The obtained modeling results presented in terms of Pareto fronts of non-dominated solutions and the compromise solutions depicted among them. The robustness of the obtained models evaluated using a Monte Carlo simulation approach for different uncertainty levels. Statistical indices such as cumulative distribution functions (CDFs) and probability density functions (PDFs) are used to show the robustness of the optimum GP-based mathematical model. An optimization procedure is also performed using a differential evolution algorithm based on the obtained models. The discrepancy between maximum and minimum output voltage in the whole operation of the system is chosen as the optimization process objective function which sought to be minimized.

\section{Modeling and optimization method}

Genetic programming is one of the optimization methods based on evolutionary computation which known by its treebase structure. GP imitates the fundamental laws of Darwinian theory and natural selection. It has the ability to express a complex structure in a symbolic fashion. Each tree is a combination of some nodes and branches constituted various structures. These nodes consist of functions and terminals that should be chosen according to the problem. The set of functions includes operators, mathematical functions, condition expressions, and so on. The set of terminals includes variables and constants. To GP explores the searching space for better fitted solutions, the principles of evolutionary operations like crossover and mutation should be applied on the initial population [12].

In this work, previously developed multi-objective uniform-diversity genetic-programming code is used for Pareto modeling of RSOCs. Further details of this algorithm can be found in $[24,25]$. Experimental data of reversible operation with Ni-YSZ anode and LSM-YSZ cathode materials are gathered from the literature [26, 27]. The input parameters are temperature, current density, and fuel composition, while output voltage is considered as the output of the system. Training error and structure complexity of the evolved mathematical models by GP are assumed as objective functions of multi-objective procedure. The obtained results of multi-objective modeling are expressed as the first Pareto front of non-dominated solutions, which the trade-off optimum model depicted among them. Such data-driven models 
should be robust and reliable to be used for practical system design and optimization purposes due to various sources of uncertainties. For this reason, a stochastic approach based on Monte Carlo simulations is used to show the robustness of the obtained model for various uncertainty levels. Statistical indices such as cumulative distribution functions and probability density functions are used to evaluate the robustness performance of obtained trade-off model.

Finally, an optimization process applied based on the obtained optimum model to optimize the input parameters using a differential evolution (DE) algorithm. DE is an efficient stochastic population-based method which uses real parameters in the entire cycle of convergence for searching over design space [28]. Because of its simplicity and excellent convergence characteristics, DE has been successfully applied to the wide range of problems which are nonlinear and constrained. The flowchart of the whole methodology is depicted in Fig. 1.

\section{Stochastic analysis method}

There are commonly two types of uncertainties: aleatory and epistemic [29, 30]. Aleatory uncertainties are associated with physical variability (e.g., material properties, operating condition manufacturing, and tolerance) in the system and environment which are typically handled using probabilistic methods. Epistemic uncertainties are referring to those that are due to the lack of knowledge (e.g., model assumptions) and can be reduced by increasing our knowledge of the system, for example, by performing more experiments. In this study, we have just considered aleatoric uncertainty.

MCS is a direct and simple numerical method for uncertainty quantification and is used in this research for stochastic analysis of obtained optimum design solutions [21]. It generates random samples considering pre-defined probabilistic distributions for uncertain parameters. Such analysis determines robustness of the system output indices when the input variables subjected to some degrees of uncertainties. To analyze the robustness of a system, statistical methods should be employed to reflect the probabilistic nature of uncertain variables of the system.

In this study, a Monte Carlo Simulation approach has been used to perform a random sampling process assuming a predefined probabilistic distribution for unsure design variables. A random number drawn out from a normal distribution over the interval $[0,1]$ is used to generate samples from the inverse cumulative distribution function.

Let $\mathrm{X}$ be a random variable, then the common model for uncertainties in stochastic randomness is the probability density function (PDF), $f_{X}(x)$ or equivalently the cumulative distribution function $(\mathrm{CDF}), F_{X}(x)$, where the subscript $X$ refers to the random variable. This can be presented by Eq. (1):

$F_{X}(x)=\operatorname{Pr}(X \leq x)=\int_{-\infty}^{x} f_{X}(x) \mathrm{d} x$

where $\operatorname{Pr}($.$) is the probability that an event (X \leq x)$ will occur. Some statistical moments such as the first and second

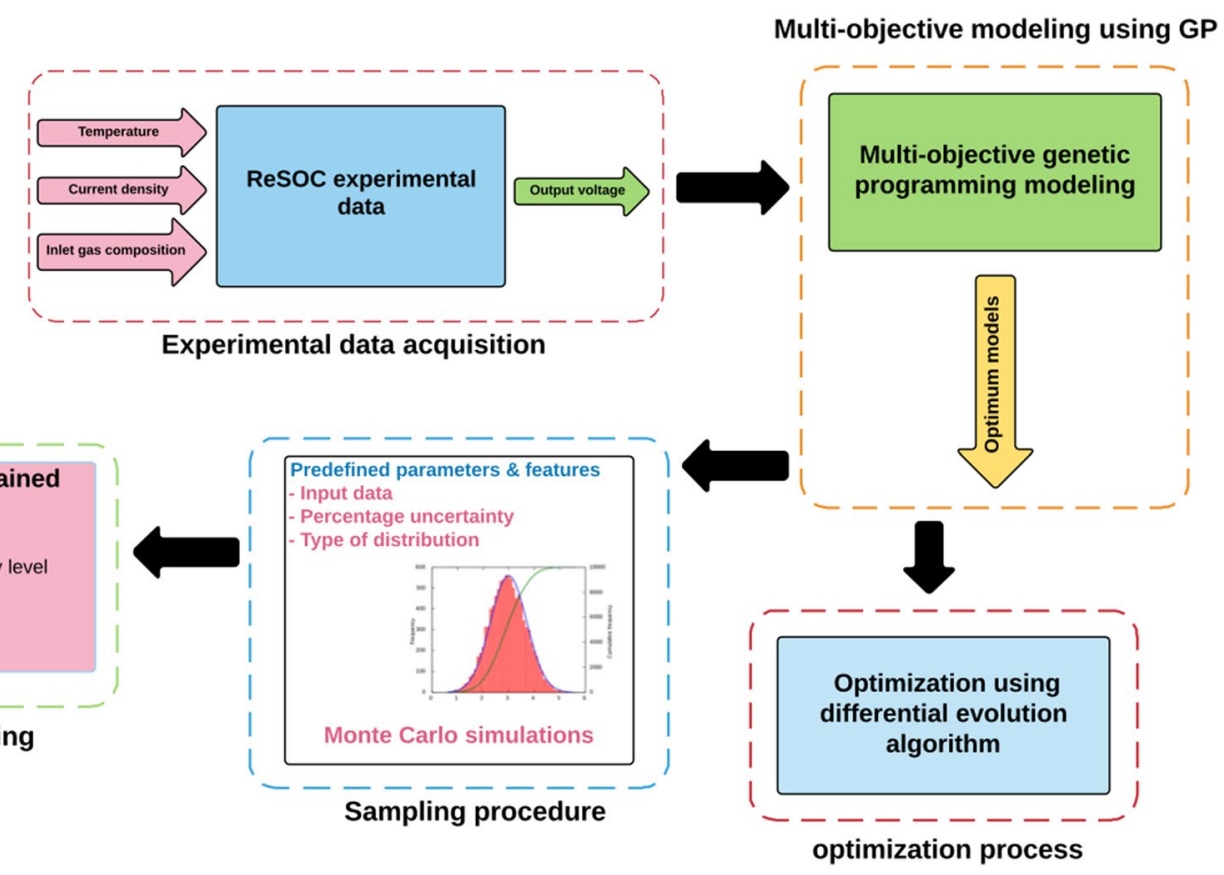

Fig. 1 Flowchart of proposed approach 
moments, generally known as mean value denoted by $\mu(X)$ and variance denoted by $\sigma^{2}(X)$, respectively, are of the most important ones. In the case of discrete sampling, these functions can be shown in Eqs. (2) and (3):

$\mu(X) \cong \frac{1}{N} \sum_{i=1}^{N} x_{i}$

$\sigma^{2}(X)=\operatorname{Var}(X) \cong \frac{1}{N-1} \sum_{i=1}^{N}\left(x_{i}-\mu(x)\right)^{2}$

where $x_{i}$ is the $i$ th sample and $N$ is the total number of samples. In addition, Gaussian distribution expressed in Eq. (4) is used for generating random samples:

$f(x)=\frac{1}{\sigma \sqrt{2 \pi}} \exp \left[\frac{-1}{2}\left(\frac{x-\mu}{\sigma}\right)^{2}\right]-\infty<x<\infty$.

\section{Results and discussion}

\section{Multi-objective modeling using genetic programming}

A multi-objective genetic-programming code developed in Matlab is used for Pareto modeling of solid oxide cells in reversible operation. The used parameters of GP algorithm are given in Table 1. A total number of 248 experimental input-output data of Ni-YSZ and LSM-YSZ cells in reversible operation collected from $[26,27]$ are used for the modeling. $65 \%$ of the whole data are used as the training set for modeling and the rest are used as unseen testing data set. The range of used input data are given in Table 2.
After the optimization process, just nine points remained non-dominated to each other. The Pareto front of obtained non-dominated solutions and the critical points are shown in Fig. 2. Point $A$ has the minimum training error, point $B$ has the simplest structure, and point $\mathrm{C}$ chosen as the trade-off design solution. It should be noted that the trade-off point can be selected from the non-dominated solutions based on the designer preferences. The objective functions and design variables of points A-C are given in Table 3. The mathematical expression corresponded to point $\mathrm{C}$ is also given in Eq. (5). It can be seen from this equation that the depicted optimum model corresponds to tree length of 6 has a simple structure:

$$
\begin{aligned}
V_{\text {out }}= & {\left[\frac{\exp \left(I+x_{\mathrm{H}_{2} \mathrm{O}} x_{\mathrm{CO}_{2}}\right)}{\operatorname{Cos}\left(x_{\mathrm{CO}}\right)}\right] } \\
& \left(\frac{759.06}{x_{\mathrm{CO}}-T-79.98}+T^{x^{x} \mathrm{C}_{2}}+\operatorname{Ln}\left(x_{\mathrm{CO}_{2}}\right)\right) \times\left(\log _{2}\left(\log _{2} \frac{x_{\mathrm{H}_{2}}}{x_{\mathrm{CO}}}\right)+x_{\mathrm{H}_{2} \mathrm{O}}^{x_{2} \mathrm{O} \log _{10}} \frac{x_{\mathrm{H}_{2}}}{110.52}\right) .
\end{aligned}
$$

Comparison of the suggested model outputs and actual values of RSOC voltage are shown in Fig. 3 for both training and prediction data. As can be seen from this figure, the square of the correlation coefficient (R2) of 0.97 and 0.95 is obtained for training and prediction sets, respectively.

Table 2 Upper and lower bounds of input data

\begin{tabular}{llc}
\hline Design variable & Upper bound & Lower bound \\
\hline Current density $\left(\mathrm{A} / \mathrm{cm}^{2}\right)$ & 1 & -1 \\
Temperature $\left({ }^{\circ} \mathrm{C}\right)$ & 850 & 750 \\
$\mathrm{H}_{2}$ mole fraction & 0.5 & 0 \\
$\mathrm{H}_{2} \mathrm{O}$ mole fraction & 0.5 & 0 \\
$\mathrm{CO}$ mole fraction & 0.5 & 0 \\
$\mathrm{CO}_{2}$ mole fraction & 0.5 & 0 \\
\hline
\end{tabular}

Table 1 Multi-objective genetic-programming parameters

\begin{tabular}{ll}
\hline Population size & 500 \\
Number of iterations & 200 \\
Maximum tree length & 15 \\
Maximum initial tree length & 6 \\
Probability of crossover & 0.9 \\
Probability of mutation & 0.1 \\
Probability of integer alteration operator & 0.6 \\
Fitness selection method & Binary tournament selection \\
Tournament size & 4 \\
Stopping criteria & Maximum generation \\
Original population & Half Full tree, Half Grow tree \\
$\varepsilon$-elimination threshold value & 0.01 \\
Function set & $\{$ PLUS, MULTIPLE, MINUS, DIVIDE, TAN, ATAN, \\
& POWER, ABS, SIN, COS, RADICAL, EXPONEN- \\
Terminal set & TIAL, Ln $\}$ \\
\hline
\end{tabular}


Fig. 2 Pareto front of nondominated solutions in the plane of RMSE and tree length

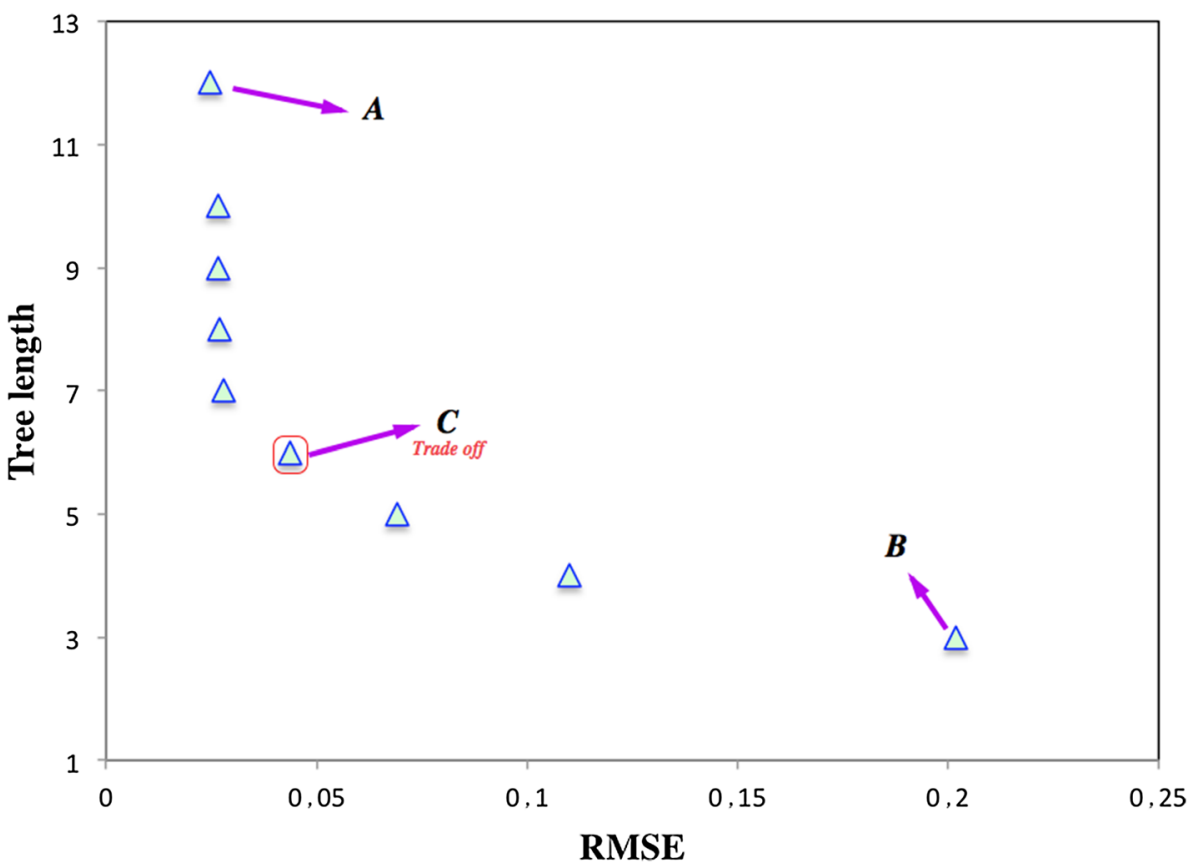

Table 3 Critical points of multi-objective modeling using GP

\begin{tabular}{llll}
\hline & Point A & Point B & Point C \\
\hline RMSE & 0.024 & 0.20 & 0.043 \\
Tree length & 12 & 3 & 6 \\
\hline
\end{tabular}

To better show the performance of the proposed model on the training and prediction data, the experimental and modeling data of $I-V$ curves for some experiments are illustrated in Fig. 4. Various experimental data with different temperature and fuel compositions are used to verify the obtained GP model for training and prediction sets in Fig. 4a, b, respectively. The fuel mixture is balanced with Argon in all cases for verification and parametric analysis through this work. It should be noted that the testing data (Fig. 4b) are unseen data from different experiments. From Fig. 4, good prediction capability of the model can be seen for both data sets. However, the model has some limitations to track the experimental data at high current densities, where the mass transport effects are dominant. This is while it was well discussed in the literature that the best performance of RSOCs system in terms of efficiency is obtained at low current densities near the OCV region, where the overpotential is in the linear region. Hence, in this study, the parametric analysis and optimization works performed at low current densities.
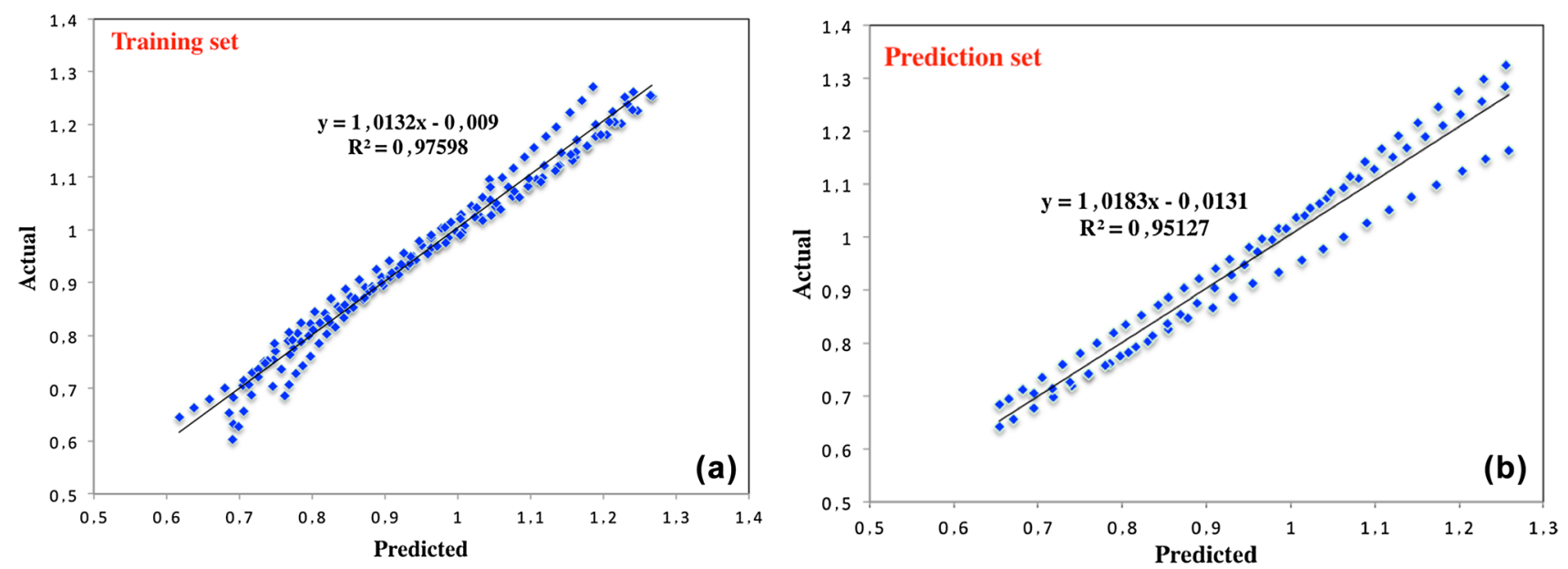

Fig. 3 Comparison of the actual values versus the evolved optimum GP model for both training and prediction sets 

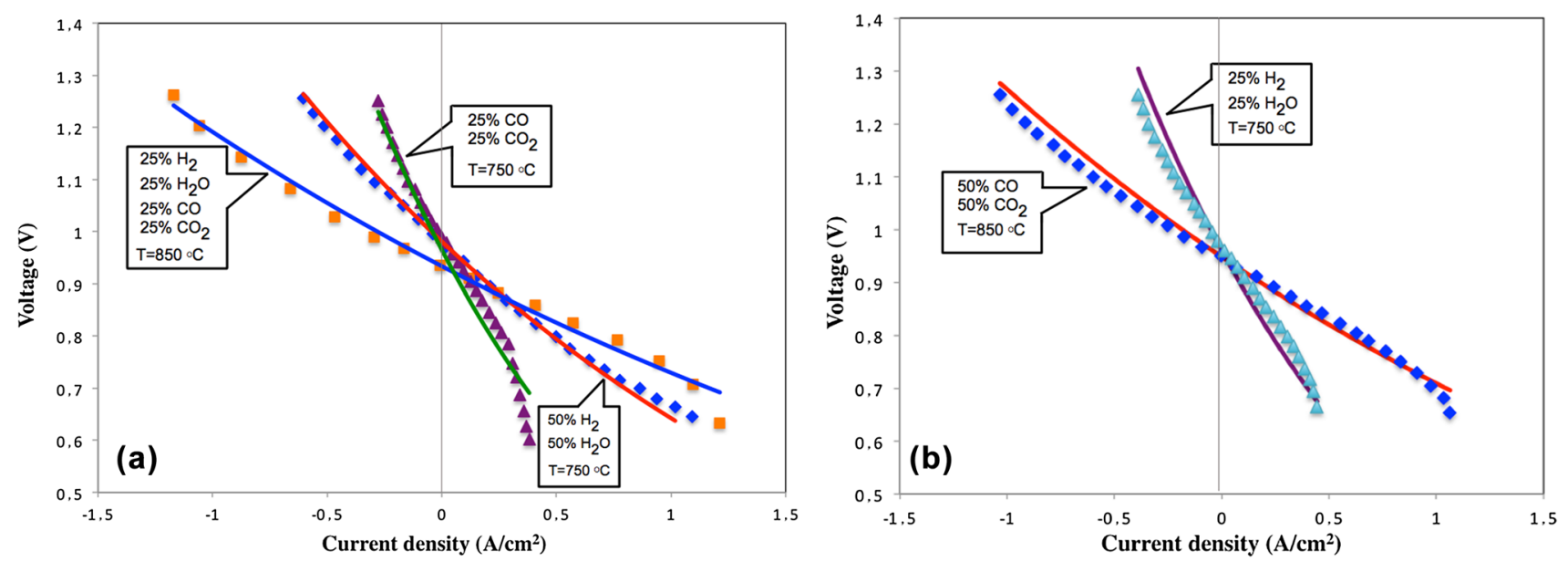

Fig. 4 Comparison of the experimental data and modeled ones for various inlet condition: $\mathbf{a}$ training set and $\mathbf{b}$ prediction set

\section{Uncertainty analysis of the optimum trade-off model}

In this section, a Monte Carlo simulation-based approach defined in "Stochastic analysis method" section is used to show the robustness performance of optimum GP model. Based on the normal distribution, 5000 samples generated around the experimental input data $\left(I, T, x_{i}\right)$, with a predefined uncertainty interval (1-10\%). In this way, instead of one data set table, 5000 data set tables produced. Second, the output of all 5000 table data sets measured based on the obtained model (Eq. 5). Finally, based on the obtained output voltages from Eq. 5, the system statistical characteristics are calculated using Eqs. 1-3.
The CDF plots of RMSE are depicted in Fig. 5a. In this figure, different uncertainty levels (1, 3, 5, 7, and 10\%) are assumed for the robustness analysis. Such CDF plots are useful for understanding the system output sensitivity to different levels of uncertainty in input parameters. Furthermore, the necessity of using robust modeling methods for the system can also be analyzed. It can be seen from Fig. 5a that the proposed model has robust performance for uncertainty levels around 5\%, which is a typical value in practice. The exact values of mean RMSE and standard deviation of RMSE for various uncertainties are given in Table 4.

Moreover, deviation from the mean values can be well illustrated by PDF plots. In this way, the PDF plots of the suggested optimum model have been demonstrated for 3 and 7\% uncertainties in Fig. 5b, c, respectively.
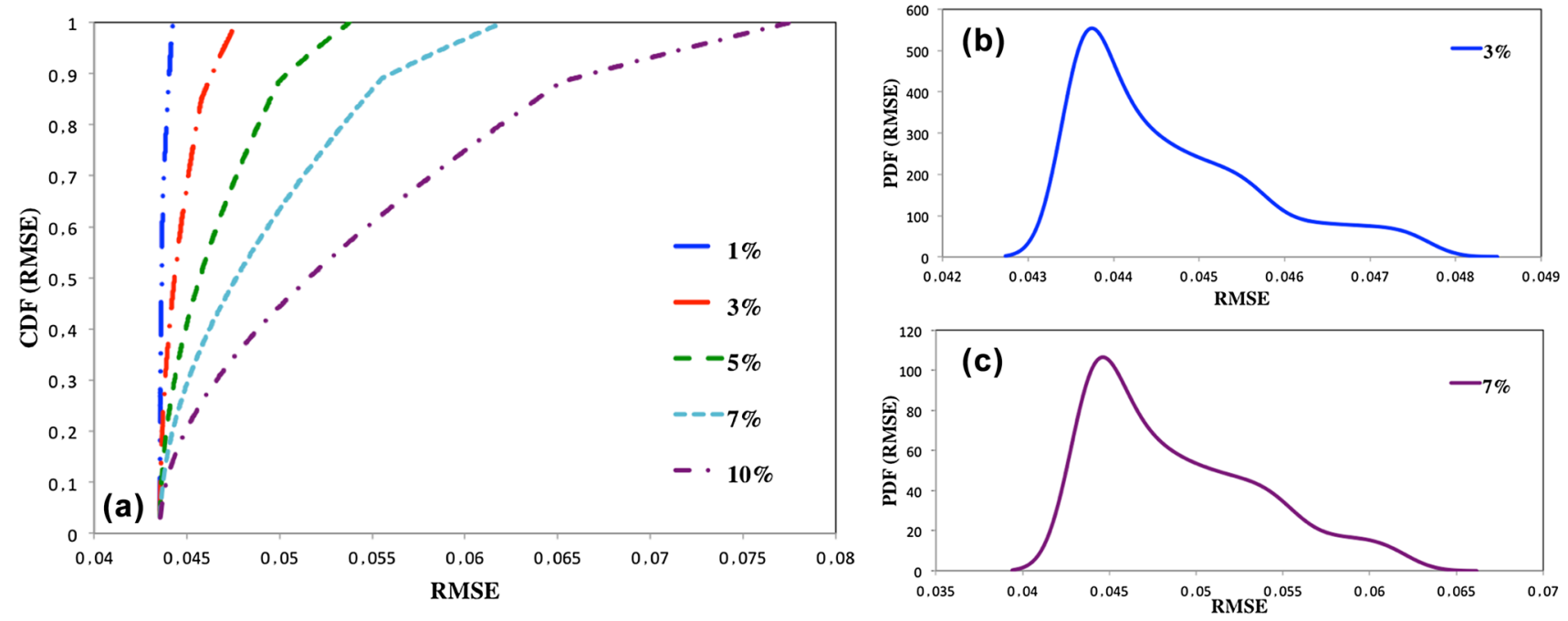

Fig. 5 Stochastic performance of optimum GP model a CDF of RMSE for various uncertainties, b PDF of RMSE with 3\% uncertainty, and $\mathbf{c}$ PDF of RMSE with 7\% uncertainty 
Table 4 Mean and SD of RMSE obtained by MCSs with 5000 samples for various uncertainty levels

\begin{tabular}{llllll}
\hline & $1 \%$ & $3 \%$ & $5 \%$ & $7 \%$ & $10 \%$ \\
\hline Mean (RMSE) & 0.044 & 0.045 & 0.067 & 0.049 & 0.054 \\
SD (RMSE) & $1.94 \mathrm{e}-4$ & 0.001 & 0.0026 & 0.0048 & 0.009 \\
\hline
\end{tabular}

\section{Parametric analysis}

In this section, the proposed optimum robust model given in Eq. (5) is used to show the effect of various input parameters on the output variables of interest such as power density and voltage. The effect of temperature for two different fuel compositions at 750 and $850{ }^{\circ} \mathrm{C}$ is depicted in Fig. 6. Figure 6 a shows output voltage and power density variations for different current densities from -1 to $1 \mathrm{~A} / \mathrm{cm}^{2}$ at 750 and $850{ }^{\circ} \mathrm{C}$. The fuel mixture is considered as $25 \% \mathrm{H}_{2}, 25 \% \mathrm{CO}$, $25 \% \mathrm{CO}_{2}$, and $25 \% \mathrm{H}_{2} \mathrm{O}$. In this case, power density $(P)$ is improved by about $0.13 \mathrm{~W} / \mathrm{cm}^{2}$ by increasing temperature from 750 to $850{ }^{\circ} \mathrm{C}$ reaching at $0.72 \mathrm{~W} / \mathrm{cm}^{2}$ in the fuel cell operation. In the opposite trend, in the electrolyser mode of operation, power density is increased about $0.13 \mathrm{~W} / \mathrm{cm}^{2}$ by decreasing temperature from 850 to $750{ }^{\circ} \mathrm{C}$ reaching at $-1.47 \mathrm{~W} / \mathrm{cm}^{2}$ at the current density of $-1 \mathrm{~A} / \mathrm{cm}^{2}$.

The same variation trend can be seen from Fig. $6 \mathrm{~b}$ for the inlet composition of $25 \% \mathrm{H}_{2}, 25 \% \mathrm{CO}$, and $50 \% \mathrm{H}_{2} \mathrm{O}$. In this case, the overpotential increased by $0.17 \mathrm{~V}$ in the fuel cell mode and $0.25 \mathrm{~V}$ in the electrolyser mode as a result of temperature reduction by $100{ }^{\circ} \mathrm{C}$. It can be also seen that by increasing $\mathrm{H}_{2} \mathrm{O}$ content instead of $\mathrm{CO}_{2}$ power density of the system improved. For instance, by comparing Fig. 6a, b, about $0.02 \mathrm{~W} / \mathrm{cm}^{2}$ increase can be seen in power density at $850{ }^{\circ} \mathrm{C}$. In addition, here, the OCV slightly increase by temperature reduction for both case studies. The effects of temperature on system performance based on the

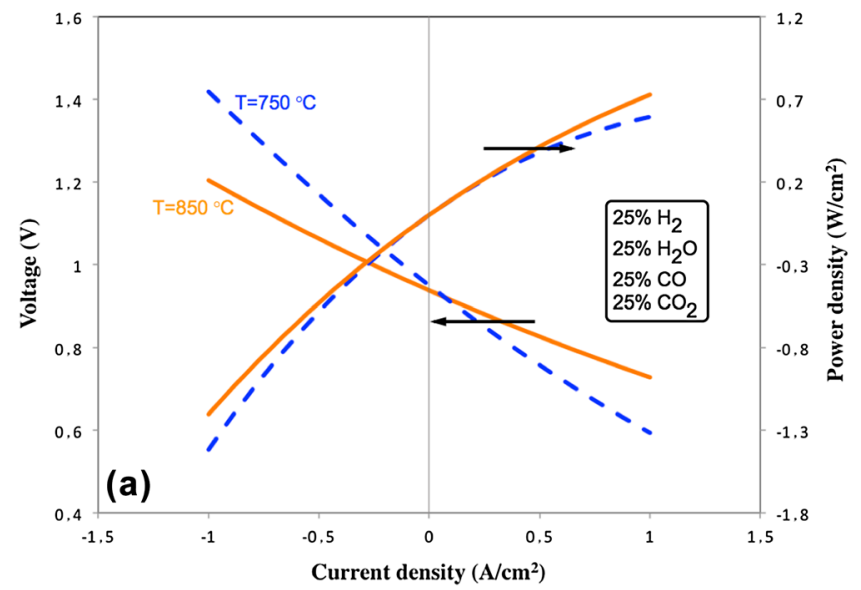

Fig. 6 Effect of temperature on output voltage and power density current model are analogous to experimental observations of Ebbesen et al. [26].

Figure 7 depicts the effect of various fuel compositions at a constant temperature $\left(750{ }^{\circ} \mathrm{C}\right)$ over the negative to positive current densities. Figure $7 \mathrm{a}, \mathrm{b}$ evaluates such performance for binary systems of gases mixtures. As it is expected, steam electrolysis has less overpotential than carbon dioxide electrolysis in the same temperature and mole fraction. Similarly, in the fuel cell mode, fuel mixture of 50\% $\mathrm{H}_{2}-50 \% \mathrm{H}_{2} \mathrm{O}$ shows power density of $0.67 \mathrm{~W} / \mathrm{cm}^{2}$ compared to $0.53 \mathrm{~W} / \mathrm{cm}^{2}$ for $50 \% \mathrm{CO}-50 \% \mathrm{CO}_{2}$ mixture. These figures also illustrated the effect of $\mathrm{CO}$ and $\mathrm{H}_{2}$ content on both operating modes. As it can be observed, decreasing the amount of $\mathrm{CO}$ and $\mathrm{H}_{2}$ species will increase the overpotential of the cell in both operating regimes. Such trends can also be seen from experimental work of Ebbesen et al. [26].

Furthermore, Fig. 7c, d shows the effect of various fuel mixtures on power density and output voltage. Figure $7 \mathrm{c}$ compared the $I-V$ and $I-P$ curves of $25 \% \mathrm{CO}-25 \% \mathrm{CO}_{2}$ versus $25 \% \mathrm{H}_{2}-25 \% \mathrm{CO}-25 \% \mathrm{H}_{2} \mathrm{O}$ fuel compositions. This figure suggests that the overpotential for $\mathrm{CO}_{2}$ electrolysis is much higher than $\mathrm{H}_{2} \mathrm{O}$ electrolysis in the considered condition. In the fuel cell mode, also as it is expected, the higher overpotential was for $\mathrm{CO}$ oxidation. Figure $7 \mathrm{~d}$ shows that co-electrolysis of $\mathrm{H}_{2} \mathrm{O}$ and $\mathrm{CO}_{2}$ constituted less overpotential than $\mathrm{H}_{2} \mathrm{O}$ electrolysis. On the other hand, in the fuel cell mode, at higher current densities, $\mathrm{CO}$ oxidation with $50 \%$ volume fraction of fuel shows higher power densities (about $0.1 \mathrm{~W} / \mathrm{cm}^{2}$ ) compared to $\mathrm{H}_{2}$ oxidation with $25 \%$ volume fraction.

\section{Optimization of optimum GP model based on differential evolution algorithm}

In this section, a differential evolution algorithm proposed by Gholaminezhad and Jamali [31] is used for optimization

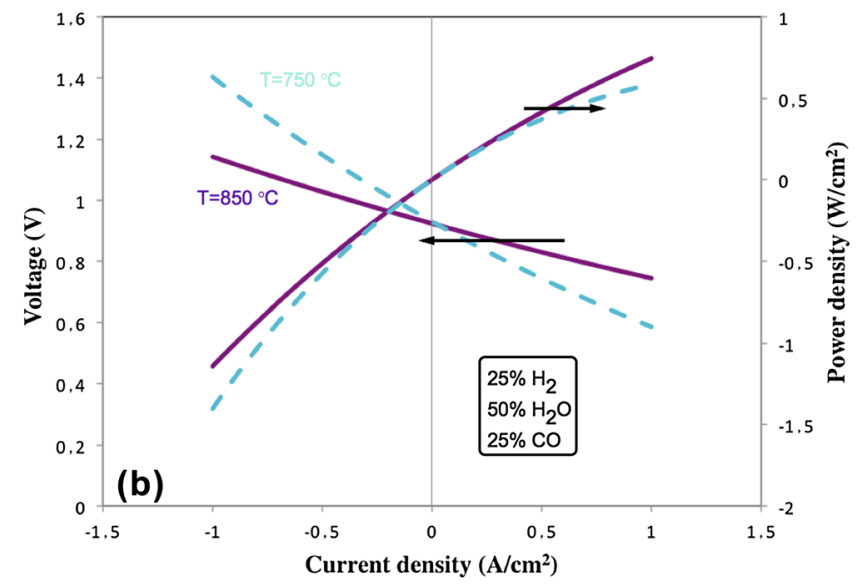



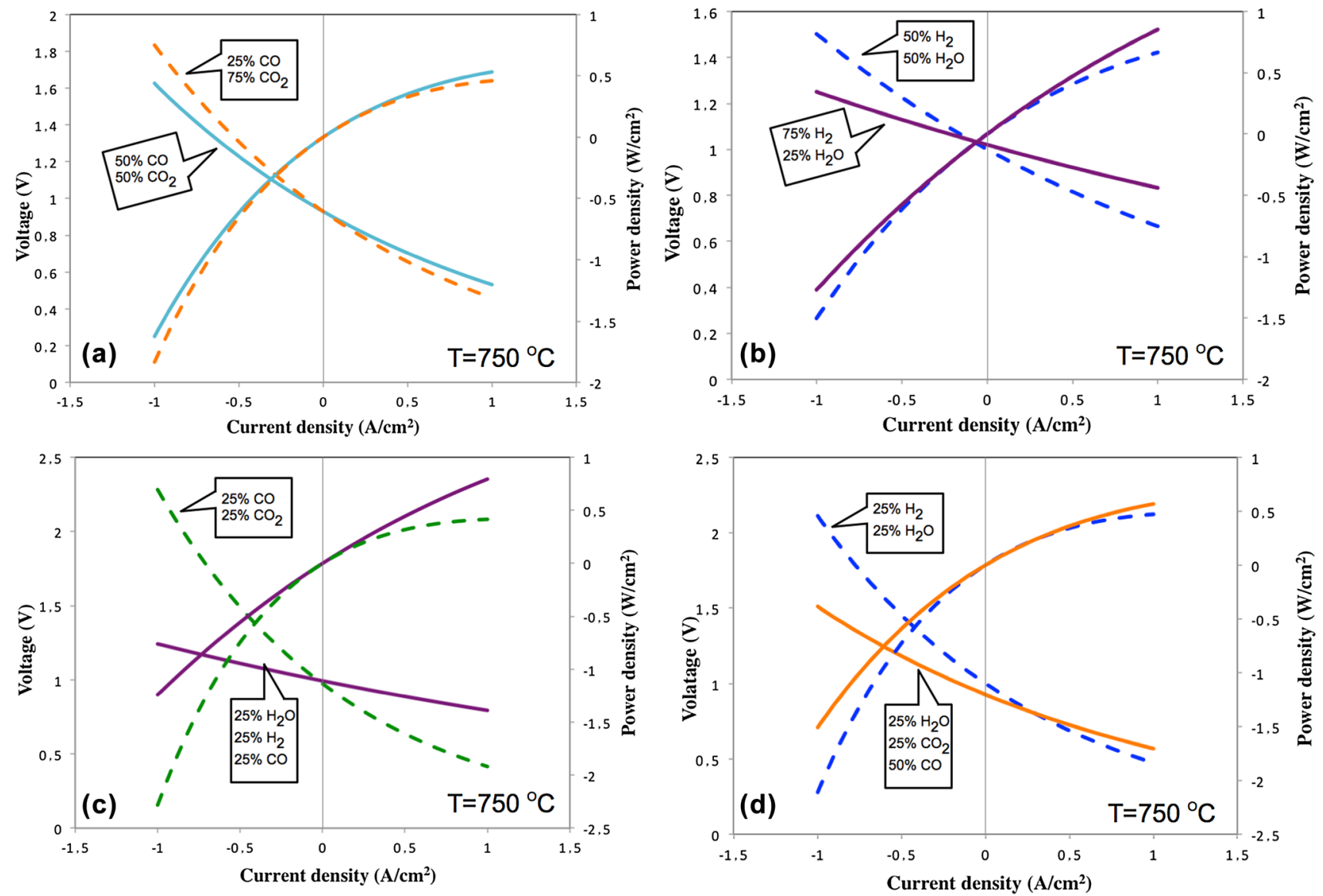

Fig. 7 Effect of various fuel mixtures on output voltage and power density

of operational variables of RSOC based on the obtained optimum model by genetic programming. Temperature, $\mathrm{H}_{2}, \mathrm{CO}, \mathrm{H}_{2} \mathrm{O}$, and $\mathrm{CO}_{2} \mathrm{~mol}$ fractions are considered as design variables. The ranges of design parameters are tabulated in Table 2. Equation (6) gives the considered objective function, which is the total overpotential in the fuel cell and electrolyser modes of operation. This objective function sought to be minimized for maximum extracted power in the fuel cell mode and minimum consumed power in the electrolyser mode. The optimization procedure implemented for current densities from -1 to $1 \mathrm{~A} / \mathrm{cm}^{2}$ :

$\mathrm{Obj}_{\text {fun }}=\eta_{\text {tot, Fuel Cell }}+\eta_{\text {tot,Electrolyser }}$.

The differential evolution parameters used for optimization study are given in Table 4. After the optimization performed, an optimum solution with total reversible overpotential of $0.35 \mathrm{~V}$ is obtained. From the total overpotential $(0.35 \mathrm{~V}), 0.16 \mathrm{~V}$ corresponds to fuel cell overpotential and $0.19 \mathrm{~V}$ corresponds to electrolyser mode. The design variables and objective functions of this optimum point are given in Table 5.
Figure 8 depicts the characteristic curves of the obtained optimum design for current densities in the considered range. The optimal condition occurred in the temperature of $762{ }^{\circ} \mathrm{C}$ and mole fractions of about $0.29,0.25$, 0 , and 0.14 for $\mathrm{H}_{2}, \mathrm{H}_{2} \mathrm{O}, \mathrm{CO}_{2}$, and $\mathrm{CO}$, respectively. The maximum power density at this condition in the fuel cell mode is about $0.84 \mathrm{~W} / \mathrm{cm}^{2}$ and the minimum power density in the electrolyser mode is approximately $-1.18 \mathrm{~W} /$ $\mathrm{cm}^{2}$. In addition, the obtained optimum design has the open circuit of $0.99 \mathrm{~V}$ at $762{ }^{\circ} \mathrm{C}$.

Table 5 Design variables and objective functions of optimum design solution by differential evolution algorithm

\begin{tabular}{ll}
\hline Design variable & Value \\
\hline Temperature $\left({ }^{\circ} \mathrm{C}\right)$ & 762 \\
$\mathrm{H}_{2}$ mole fraction & 0.287 \\
$\mathrm{H}_{2} \mathrm{O}$ mole fraction & 0.253 \\
$\mathrm{CO}$ mole fraction & 0.148 \\
$\mathrm{CO}_{2}$ mole fraction & $1.0 \mathrm{e}-7$ \\
$\mathrm{Obj}$ func $(\mathrm{V})$ & 0.35 \\
\hline
\end{tabular}


Fig. 8 Performance of the optimum design solution in terms of output voltage and power density

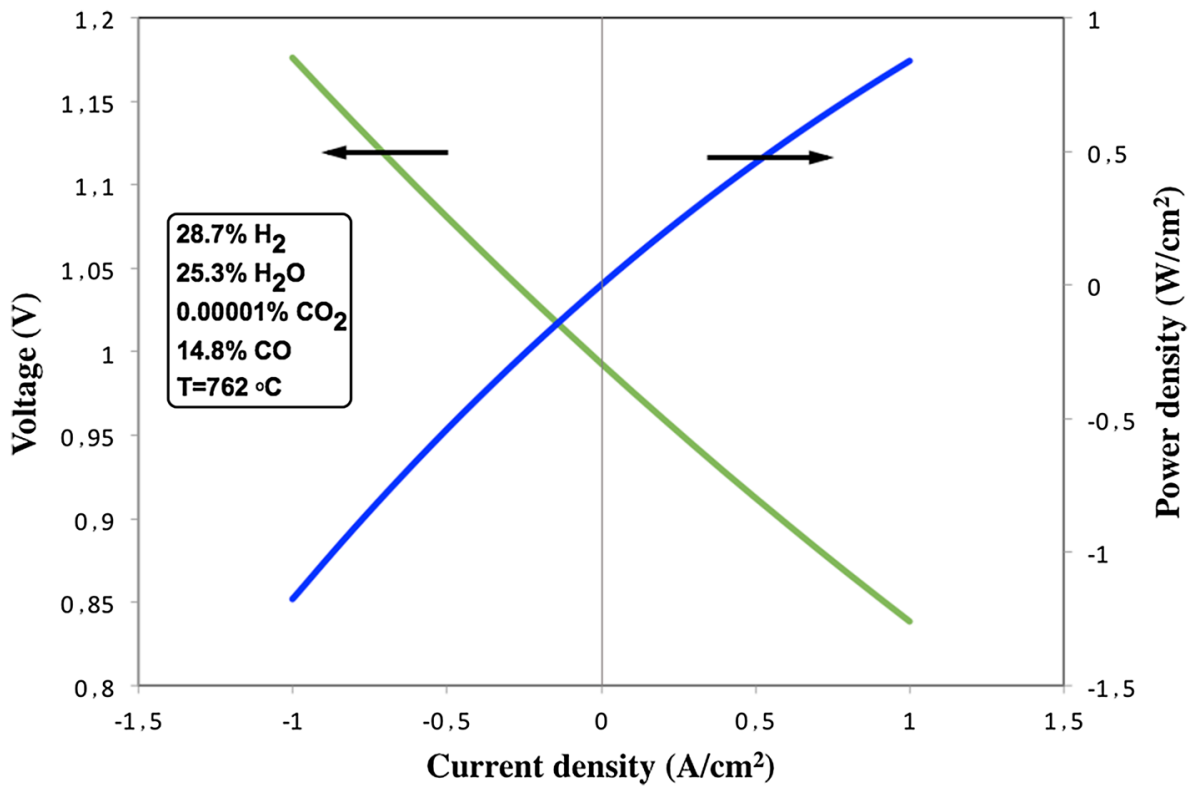

\section{Conclusion}

In this work, a multi-objective modeling approach based on genetic-programming algorithm is used for modeling of reversible solid oxide cells based on experimental input-output data. Temperature, current density, and fuel mixture are considered as input data and system voltage as the output. A Monte Carlo simulation and a differential evolution algorithm also used for uncertainty analysis and optimization of the obtained optimal model.

Correlation coefficient $\left(R^{2}\right)$ of about 0.96 is obtained for both training and prediction data sets in modeling using genetic-programming algorithm. The obtained results show that in the fuel cell mode of operation, power density improves by increase of temperature, while the opposite trend is seen for the electrolyzer mode for a constant fuel mixture. Furthermore, analysis of the effect of fuel composition showed that decreasing the amount of $\mathrm{CO}$ and $\mathrm{H}_{2}$ species will increase the overpotential of the cell in both operating regimes. In addition, the overpotential for $\mathrm{CO}_{2}$ electrolysis is much higher than $\mathrm{H}_{2} \mathrm{O}$ electrolysis, and in the fuel cell mode, the higher overpotential was for $\mathrm{CO}$ oxidation. Finally, optimal condition of the proposed model with total overpotential of 0.35 is occurred in the temperature of $762{ }^{\circ} \mathrm{C}$ and mole fractions of about 0.29 , $0.25,0$, and 0.14 for $\mathrm{H}_{2}, \mathrm{H}_{2} \mathrm{O}, \mathrm{CO}_{2}$, and $\mathrm{CO}$, respectively.

Funding This research did not receive any specific grant from funding agencies in the public, commercial, or not-for-profit sectors.

\section{Compliance with ethical standards}

Conflict of interest On behalf of all authors, the corresponding author states that there is no conflict of interest.

Open Access This article is distributed under the terms of the Creative Commons Attribution 4.0 International License (http://creativeco mmons.org/licenses/by/4.0/), which permits unrestricted use, distribution, and reproduction in any medium, provided you give appropriate credit to the original author(s) and the source, provide a link to the Creative Commons license, and indicate if changes were made.

\section{References}

1. Kazempoor, P., Braun, R.J.: Model validation and performance analysis of regenerative solid oxide cells for energy storage applications: reversible operation. Int. J. Hydrogen Energy 39, 5955-5971 (2014)

2. Wendel, C.H., Kazempoor, P., Braun, R.J.: Novel electrical energy storage system based on reversible solid oxide cells: system design and operating conditions. J. Power Sour. 276, 133-144 (2015)

3. Wendel, Christopher H., Gao, Zhan, Barnett, Scott A., Braun, Robert J.: Modeling and experimental performance of an intermediate temperature reversible solid oxide cell for high-efficiency, distributed-scale electrical energy storage. J. Power Sour. 283, 329-342 (2015)

4. Wendel, C.H., Kazempoor, P., Braun, R.J.: A thermodynamic approach for selecting operating conditions in the design of reversible solid oxide cell energy systems. J. Power Sour. 301, 93-104 (2016)

5. Jin, X., Xue, X.: Mathematical modeling analysis of regenerative solid oxide fuel cells in switching mode conditions. J. Power Sour. 195, 6652-6658 (2010) 
6. Ni, M., Leung, M.K.H., Leung, D.Y.C.: Theoretical analysis of reversible solid oxide fuel cell based on proton-conducting electrolyte. J. Power Sour. 177, 369-375 (2008)

7. Chaichana, K., Patcharavorachot, Y., Chutichai, B., Saebea, D., Assabumrungrat, S., Arpornwichanop, A.: Neural network hybrid model of a direct internal reforming solid oxide fuel cell. Int. J. Hydrogen Energy 37, 2498-2508 (2012)

8. Cheng, H., Jing, S., Xu, Y., Deng, Z., Li, J., Li, X.: Control-oriented modeling analysis and optimization of planar solid oxide fuel cell system. Int. J. Hydrogen Energy 41, 22285-22304 (2016)

9. Mohammadi, M., Raoofat, M., Marzooghi, H., Gharehpetian, G.B.: Nonlinear multivariable modeling of solid oxide fuel cells using core vector regression. Int. J. Hydrogen Energy 36, 1253812548 (2011)

10. Li, P., Ki, J.-P., Liu, H.: Analysis and optimization of current collecting systems in PEM fuel cells. Int. J. Energy Environ. Eng. 3, 2 (2012). https://doi.org/10.1186/2251-6832-3-2

11. Liu, H., Li, P., Hartz, A., Wang, K.: Effects of geometry/dimensions of gas flow channels and operating conditions on high-temperature PEM fuel cells. Int. J. Energy Environ. Eng. 6(1), 75-89 (2015)

12. Koza, J.R.: Genetic Programming: On the Programming of Computers by Means of Natural Selection. MIT Press. ISBN 0-262$11170-5(1992)$

13. Chakraborty, U.K.: Static and dynamic modeling of solid oxide fuel cell using genetic programming. Energy 34, 740-751 (2009)

14. Chakraborty, U.K.: Genetic programming model of solid oxide fuel cell stack: first results. Int. J. Inf. Commun. Technol. (IJICT) 1(3/4), 453-461 (2008)

15. Nazari, A.: Prediction performance of PEM fuel cells by gene expression programming. Int. J. Hydrogen Energy 37, 18972 18980 (2012)

16. Bozorgmehri, S., Hamedi, M.: Modeling and optimization of anode-supported solid oxide fuel cells oncell parameters via artificial neural network and genetic algorithm. Full Cells 12(1), 11-23 (2012)

17. Behzadi Forough, A., Roshandel, R.: Multi-objective optimization of solid oxide fuel cell stacks considering parameter effects: fuel utilization and hydrogen cost. J. Renew. Sustain. Energy 5(5), 053124 (2013). https://doi.org/10.1063/1.4822253

18. Quddus, M.R., Zhang, Y., Ray, A.K.: Multi-objective optimization in solid oxide fuel cell for oxidative coupling of methane. Chem. Eng. J. 165, 639-648 (2010)

19. Borji, M., Atashkari, K., Nariman-zadeh, N., Masoumpour, M.: Modeling, parametric analysis and optimization of an anode-supported planar solid oxide fuel cell. Proc IMechE Part C: J Mech. Eng. Sci. 1-16 (2015)
20. Gholaminezhad, I., Jafarpur, K., Paydar, M.H., Karimi, G.: Multiscale multi-objective optimization and uncertainty analysis of methane-fed solid oxide fuel cells using Monte Carlo simulations. Energy Convers. Manage. 153, 175-187 (2017)

21. Rubinstein, R.Y.: Simulation and the Monte Carlo method. Wiley, New York (1981)

22. Xu, L., Fang, C., Hu, J., Cheng, S., Li, J., Ouyang, M., Lehnert, W.: Parameter extraction and uncertainty analysis of a proton exchange membrane fuel cell system based on Monte Carlo simulation. Int. J. Hydrogen Energy 42, 2309-2326 (2017)

23. Taghavifar, H.: Towards multiobjective Nelder-Mead optimization of a HSDI diesel engine: application of Latin hypercube designexplorer with SVM modeling approach. Energy Convers. Manage. 143, 150-161 (2017)

24. Jamali, A., Khaleghi, E., Gholaminezhad, I., Nariman-zadeh, N.: Modelling and prediction of complex non-linear processes by using Pareto multi-objective genetic programming. Int. J. Syst. Sci. https://doi.org/10.1080/00207721.2014.945983

25. Gholaminezhad, I., Assimi, H., Jamali A., Vajari, D.A.: Uncertainty quantification and robust modeling of selective laser melting process using stochastic multi-objective approach. Int. J. Adv. Manuf. Technol. https://doi.org/10.1007/s00170-015-8238-0

26. Ebbesen, S.D., Knibbe, R., Mogensen, M.: Co-electrolysis of steam and carbon dioxide in solid oxide cells. J. Electrochem. Soc. 159(8), F482-F489 (2012)

27. Ebbesen, S.D., Graves, C., Mogensen, M.: Production of synthetic 24 by co-electrolysis of steam and carbon dioxide. Int. J. Green Energy 6(6), 646-660 (2009). https://doi.org/10.1080/15435 070903372577

28. Storn, R., Price, K.: Differential evolution: a simple and efficient heuristic scheme for global optimization over continuous spaces. J. Glob. Optim. 11, 341-359 (1997)

29. Sarangi, S., Bodla, K.K., Garimella, S.V., Murthy, J.Y.: Manifold microchannel heat sink design using optimization under uncertainty. Int. J. Heat Mass Transf. 69, 92-105 (2014)

30. Bodla, K.K., Murthy, J.Y., Garimella, S.V.: Optimization under uncertainty applied to heat sink design. J. Heat Transf. 135(1), 011012 (2013). https://doi.org/10.1115/1.4007669

31. Gholaminezhad, I., Jamali, A.: A multi-objective differential evolution approach based on $\varepsilon$-elimination uniform-diversity for mechanism design. Struct. Multidisc. Optim. https://doi. org/10.1007/s00158-015-1275-3

Publisher's Note Springer Nature remains neutral with regard to urisdictional claims in published maps and institutional affiliations. 